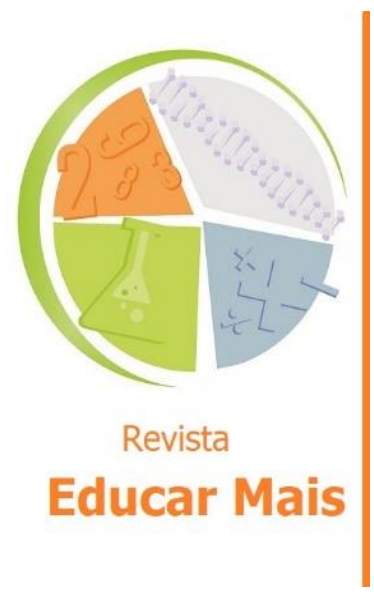

\title{
O modelo híbrido da sala de aula invertida no Ensino de Fisioterapia: uma revisão sistemática da literatura
}

\author{
The blended model of the flipped classroom in teaching in \\ Physiotherapy: a systematic review of literature
}

\section{El modelo de aula híbrida invertido en la enseñanza de la Fisioterapia: una revisión sistemática de la literatura}

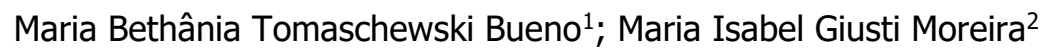

\section{RESUMO}

Este artigo é um recorte da dissertação, ainda em andamento, intitulada 'O Modelo da Sala de Aula Invertida como Proposta no Ensino de Fisioterapia: Um estudo de caso no conteúdo de Incontinência Urinária Feminina', do Programa de Pós-graduação do Instituto Federal Sul-rio-grandense do Campus Pelotas - Visconde da Graça. $O$ artigo em questão trata-se de uma revisão sistemática da literatura a qual foi delimitado em artigos no idioma português, disponíveis e completos na íntegra, sem a delimitação do período de publicação e os descritores utilizados nas buscas foram 'ensino híbrido', 'sala de aula invertida', 'educação em saúde', 'ensino em saúde', 'fisioterapia', 'metodologias ativas', 'ensino' e 'incontinência urinária'. As bases de dados escolhidas foram o Portal CAPES, o SciELO, o Portal BVS, o PubMed e o Google Acadêmico. O total de artigos encontrados foram 944, no entanto apenas 3 artigos estavam de acordo com os objetivos desse trabalho. Como a escassez de publicações científicas destinadas aos docentes da área, acredita-se que com isso, há angústias e receios para a aplicabilidade do modelo, seja esse o da Sala de Aula Invertida seja qualquer outro modelo híbrido.

Palavras-chave: Modelos Flexíveis; Ensino em Saúde; Ensino Superior; Metodologias Ativas.

\begin{abstract}
This article is an excerpt from the dissertation, still in progress, entitled 'The Flipped Classroom Model as a Proposal in Physical Therapy Teaching: A case study in the content of Female Urinary Incontinence', from the Postgraduate Program of the Instituto Federal Sul-rio-grandense, Pelotas - Visconde da Graça Campus. The article in question is a systematic review of the literature which was delimited in articles in Portuguese, available and complete in full, without delimitation of the publication period and the descriptors used in the searches were 'blended learning', 'flipped classroom', 'health education', 'health teaching', 'physiotherapy', 'active methodologies', 'teaching' and 'urinary incontinence'. The databases chosen were the CAPES Portal, SciELO, the BVS Portal, PubMed and Google Scholar. The total number of articles found was 944, however only 3 articles were in accordance with the objectives of this work. As the scarcity of scientific publications aimed at teachers in the area, it is believed that with this, there are anxieties and fears for the applicability of the model, whether that of the Flipped Classroom or any other blended model.
\end{abstract}

Keywords: Flexible Models; Health Education; Education Higher; Active Methodologies.

\footnotetext{
${ }^{1}$ Mestranda em Ciências e Tecnologias na Educação, pelo Instituto Federal de Educação, Ciência e Tecnologia Sul-rio-grandense - Câmpus Pelotas Visconde da Graça, RS, Brasil. E-mail: bethaniatomaschewsky@gmail.com

2 Doutora em Ciência da Computação e Professora do Programa de Pós-graduação em Ciências e Tecnologias na Educação do Instituto Federal de Educação, Ciência e Tecnologia Sul-rio-grandense - Câmpus Pelotas Visconde da Graça, RS, Brasil. E-mail: isabelmoreira@gmail.com
} 


\section{RESUMEN}

Este artículo es un recorte de la disertación, aún en curso, titulada "El modelo de aula invertida como propuesta en la enseñanza de la fisioterapia: un estudio de caso en el contenido de la incontinencia urinaria femenina", del Programa de Postgrado del Instituto Federal Sul-rio-grandense, Pelotas - Campus Visconde da Graça. El artículo en cuestión es una revisión sistemática de la literatura que se delimitó en artículos en lengua portuguesa, disponibles y completos en su totalidad, sin la delimitación del período de publicación y los descriptores utilizados en las búsquedas fueron "enseñanza híbrida", "aula invertida", "educación para la salud", "enseñanza de la salud", "fisioterapia", "metodologías activas", "enseñanza" e "incontinencia urinaria". Las bases de datos elegidas fueron el Portal CAPES, SCIELO, el Portal BVS, PubMed y Google Académico. El número total de artículos encontrados fue de 944, sin embargo sólo 3 artículos se ajustaban a los objetivos de este trabajo. Como la escasez de publicaciones científicas destinadas a los profesores en el área, se cree que con esto, hay ansias y temores por la aplicabilidad del modelo, ya sea el Aula Inversa o cualquier otro modelo híbrido.

Palabras clave: Modelos Flexibles; Educación para la salud; Enseñanza superior; Metodologías Activas.

\section{INTRODUÇÃO}

Este artigo é um recorte da dissertação, ainda em andamento, intitulada 'O Modelo da Sala de Aula Invertida como Proposta no Ensino de Fisioterapia: Um estudo de caso no conteúdo de Incontinência Urinária Feminina', do Programa de Pós-graduação em nível de Mestrado em Ciências e Tecnologias na Educação do Campus Pelotas - Visconde da Graça do Instituto Federal de Educação, Ciência e Tecnologia Sul-rio-grandense. A pesquisa da dissertação possui a abordagem do modelo da Sala de Aula Invertida apoiado nas Tecnologias Digitais de Informação e Comunicação como proposta no ensino do conteúdo de Incontinência Urinária na saúde da mulher no curso de Graduação em Fisioterapia.

Nesse sentido, a problematização deu-se da seguinte forma: 'Quais as estratégias pedagógicas que podem contribuir para o ensino do conteúdo de Incontinência Urinária no curso de Graduação em Fisioterapia no modelo da Sala de Aula Invertida, apontadas por docentes da área'. A pesquisa delimitou como sujeitos da pesquisa cinco docentes que ministram a disciplina de Fisioterapia na Saúde da Mulher e dentro dessa disciplina o conteúdo de Incontinência Urinária. Esses cinco docentes são de diferentes unidades de uma Instituição Privada de Ensino, no estado do Rio Grande do Sul.

Para o embasamento da dissertação foi realizada uma revisão sistemática da literatura com a temática do Ensino Híbrido e do modelo híbrido da Sala de Aula Invertida no ensino de Fisioterapia. Igualmente, na temática delimitada no ensino de Incontinência Urinária na saúde da mulher no curso de Graduação em Fisioterapia e é esse recorde que fundamenta este artigo, com o intuito de apresentar antecipadamente dados em que promovam reflexões no meio perante a temática.

\subsection{A hibridização no contexto educacional atual}

A educação no século XXI está contextualizada nos ambientes da escola, na comunidade, no local de trabalho, nas redes sociais e nas residências dos indivíduos, isto se dá devido a inserção maciça das Tecnologias Digitais da Informação e Comunicação (TDICs) nessa sociedade. A intersecção desses ambientes por meio das Tecnologias Digitais faz com que os indivíduos de diferentes faixas etárias e diferentes contextos socioeconômicos possam obter acesso constante e veloz a todo tipo de informação, por conseguinte, reconfigurando o cenário educacional (SILVA; MACIEL, 2015; OLIVEIRA, 2018). 
Em uma sociedade cada vez mais tecnológica o contexto educacional interage de acordo com as características e anseios dessa sociedade, com isso o modo de ensinar e de aprender também se conecta as Tecnologias Digitais, dentro e fora das salas de aulas. Diante desse contexto de educação na era digital, no qual as informações circulam nas redes de forma atemporal, ilimitada, plural e que ultrapassam o espaço, como resultado, proporcionam também transformações referente aos papeis dos docentes, dos discentes e das instituições de ensino (FÜHR, 2018a; FÜHR, 2018b; FÜHR, 2019).

As instituições necessitam proporcionar ambientes flexíveis, diversificados e com recursos humanos e didáticos adequados, ao professor é indispensável atualmente que seja um aprendiz, isto é, reaprender a aprender e a ensinar, ser orientador e não transmissor de informações. $\mathrm{E}$ aos alunos necessitam se tornarem condutores de suas vidas, gerenciando criticamente os conhecimentos em conformidade com o coletivo (FÜHR, 2018a; FÜHR, 2018b; FÜHR, 2019).

Nesse sentido, o Ensino Híbrido vem como uma abordagem que corrobora com os direcionamentos atuais no contexto educacional. Para Moran (2015, p. 27), a educação sempre foi híbrida, isto é, sempre aconteceu de forma misturada, no entanto, com a acentuado uso das Tecnologias Digitais da Informação e Comunicação essa abordagem se tornou mais visível nos últimos tempos.

Ainda segundo Moran (2015), o Ensino Híbrido consiste na combinação de diversos públicos, espaços, tempos, atividades e metodologias, além disso essa hibridização nesse contexto, segundo o autor, incorpora características como a flexibilidade, mobilidade, conectividade e criticidade (MORAN, 2015). O Ensino Híbrido ou Blended Learning (também denominado de $B$-learning), é uma abordagem que mistura o ensino e a aprendizagem em sala de aula e fora dela, onde atualmente, o cenário fora da sala de aula é constantemente conduzido no ambiente online (MORAN, 2015; SILVA; MACIEL; ALONSO, 2017).

Dentro da abordagem de Ensino Híbrido há propostas denominadas de: Modelo Flex, Modelo À la Carte, Modelo Virtual Enriquecido e Modelo de Rotação. Esse último possui subdivisões como: Rotação por Estações, Laboratório Rotacional, Sala de Aula Invertida e Rotação Individual (BACICH; TANZI NETO; TREVISANI, 2015, p. 54).

O modelo da Sala de Aula Invertida ou Flipped Classroom como também é denominada, foco desta pesquisa, é descrito como a inversão do modelo da aula tradicional, isto é, o conteúdo teórico anteriormente instruído em sala de aula nesse modelo é trabalhado pelo aluno fora da escola, por meio de leituras de livros, artigos científicos, ou assistir uma videoaula ou filme, ou até mesmo a realização de um jogo, conforme planejamento do professor. Já no ambiente da sala de aula são discutidos e problematizados os conteúdos teóricos, tornando assim, o momento em sala de aula dinâmico e potencializador dos conhecimentos (CAMILLO; VARGAS; MEDEIROS, 2018; CHRISTENSEN; HORN; STAKER, 2013; BACICH; TANZI NETO; TREVISANI, 2015).

No modelo da sala de aula tradicional, o ensino é vertical, expositivo, conteudista, no qual o professor é o detentor dos saberes e logo, os alunos, ouvintes, enfileirados em uma sala de aula recebem passivamente as informações desse professor. Diferentemente do modelo ativo da Sala de Aula Invertida, proveniente do Ensino Híbrido, tem como premissa o aluno protagonista, autônomo e que o mesmo esteja ciente de sua responsabilidade frente a organização de seus estudos e desenvolvimento dos saberes (SCHNEIDERS, 2018; VALENTE, 2014a; VOGT; SOARES, 2017).

O modelo da Sala de Aula Invertida no ensino superior é demonstrado na literatura como um método gradativo nas vivências dos professores e dos alunos, visto que, atualmente a maioria dos indivíduos 
possuem contato com as Tecnologias Digitais, no entanto, não a utilizam potencialmente para a área educacional. Isto é, os indivíduos utilizam as TDICs e possuem vasto domínio sobre as mesmas, mas de modo aleatório, algumas vezes, sem o entendimento de que pode ser prazerosa a utilização desses meios para os fins educativos (SOUZA; SOUZA; DANTAS, 2018).

Sob essa ótica, o modelo da Sala de Aula Invertida apoiado nas TDICs tem por fundamento potencializar de maneira positiva o modo colaborativo, ativo, autônomo e interativo da Sala de Aula Invertida. Além disso, as TDICs com uma variedade de meios, como por exemplo, Podcast, Games, Quiz, videoaulas entre outros, aproximam a utilização dessas tecnologias no cenário educacional só que de maneira fundamentada, promovendo em sua dinâmica o entusiasmo pela busca e apropriação de conhecimentos (SUNAGA; CARVALHO, 2015; VALENTE, 2014a; VALENTE, 2018b).

Diante do cenário de transformações que vem ocorrendo em todos os níveis de ensino, principalmente no ensino superior, reverbera a inquietação de dissertar perante a práxis pedagógica sob o modelo da Sala de Aula Invertida apoiado nas Tecnologias Digitais da Informação e Comunicação no ensino de Fisioterapia. Como anteriormente mencionado, essa pesquisa foi delimitada dentro do universo do ensino de Fisioterapia a disciplina de Fisioterapia na Saúde da Mulher o conteúdo de Incontinência Urinária (IU).

\subsection{A Incontinência Urinária Feminina}

A Incontinência Urinária (IU) é uma disfunção da continência urinária e é definida como a perda involuntária de urina, seja essa perda em gotas ou volumes maiores, ocasionais ou regulares, com acometimentos em ambos os sexos e em qualquer faixa etária. Segundo a literatura, a IU acomete cerca de 50 milhões de indivíduos e há uma prevalência elevada do acometimento em mulher idosas, apesar de não ser um fator do envelhecimento fisiológico humano (MATOS et al., 2019; PITANGUI; SILVA; ARAÚJO, 2012; DEDICAÇÃO et al., 2009; OLIVEIRA; GARCIA, 2011).

O mecanismo causador da IU é multifatorial e alguns fatores são descritos na literatura para esse acometimento na mulher como o enfraquecimento dos Músculos do Assoalho Pélvico (MAP), cirurgia pélvica e de extração do útero, gravidez e múltiplos partos vaginais, perda de estrogênio após a menopausa, obesidade, tabagismo, sedentarismo e atividade física intensa. Assim como, lesões neurológicas causadas pela diabetes, esclerose múltipla, Parkinson, Acidente Vascular Encefálico, tumores cerebrais e lesões de coluna (HENKES et al., 2015; APUNG, 2013; SILVA; SOLER; WYSOCKI, 2017).

As principais tipologias da Incontinência Urinária são descritas em Incontinência Urinária de Esforço (IUE), Incontinência Urinária de Urgência (IUU) também denominada de Bexiga Hiperativa (BH) ou Hiperatividade Vesical (HV) ou Imperiosidade, Incontinência Urinária Mista (IUM), no entanto, há outras tipologias descritas na literatura como a Incontinência Urinária Postural, Incontinência Urinária Funcional, Incontinência Insensível, Incontinência Contínua, Incontinência Noturna e Incontinência Coital (ROCHA; DIAS; VIEIRA, 2020; HENKES et al., 2015; APUNG, 2013; OLIVEIRA; GARCIA, 2011; MASCARENHAS, 2011).

A intervenção fisioterapêutica é o tratamento conservador na IU, isto é, o tratamento que não utiliza medicações nem intervenções cirúrgicas, com isso é uma abordagem não invasiva, eficaz, de fácil acesso e baixo custo, proporcionando qualidade de vida as mulheres. Além disso, a intervenção fisioterapêutica atua tanto na prevenção quanto no tratamento da Incontinência Urinária. As técnicas 
fisioterapêuticas evidenciados pela literatura são a Cinesioterapia, os Cones Vaginais, o Perineômetro, o Biofeedback, a Reeducação Comportamental, a Eletroestimulação e a Estimulação Magnética Perianal (OLIVEIRA; RODRIGUES; PAULA, 2007; MARQUES; FREITAS; GUEDES; SEBBEN, 2005; CAVENAGUI et al., 2020).

Outra abordagem demonstrada como crucial na promoção e prevenção da saúde é a educação frente a temática da IU. O fisioterapeuta possui competência para além das ações práticas, como o esclarecimento e o empoderamento das mulheres, pois a IU produz nelas o constrangimento ao tratar sobre o tema, insegurança frente aos seus corpos e a diminuição de autoestima (OLIVEIRA; RODRIGUES; PAULA, 2007; MARQUES; FREITAS; GUEDES; SEBBEN, 2005; OLIVEIRA et al., 2017).

A Incontinência Urinária Feminina é uma temática em que possui uma linha tênue entre o constrangimento, a vulgarização e o entendimento, nesse sentido são fundamentais o fomento em recursos educacionais e informativos, dentro e fora dos espaços acadêmicos, para que as concepções errôneas não sejam potencializadas. Igualmente, em subsídios estrategicamente ativos para os professores e professoras em suas práticas pedagógicas, corroborando na transformação da sociedade com profissionais, nesse caso, da área da Fisioterapia reflexivos e críticos ao tema.

\section{METODOLOGIA}

O procedimento metodológico deste artigo foi a revisão sistemática da literatura. A revisão demandou complementar o embasamento da pesquisa da dissertação mencionada anteriormente e possuiu como fundamento a compreensão, perante a literatura, dos temas problematizados, isto é, o que as pesquisas científicas publicadas discorrem sobre o tema aqui proposto.

Trata-se de um tipo de investigação focada em questão bem definida, que visa identificar, selecionar, avaliar e sintetizar as evidências relevantes disponíveis. [...] As revisões sistemáticas são consideradas estudos secundários, que têm nos estudos primários sua fonte de dados. Entende-se por estudos primários os artigos científicos que relatam os resultados de pesquisa em primeira mão (GALVÃO; PEREIRA, 2014, p. 183).

Dessa forma, foi delimitado artigos no idioma português, pelo fato da pesquisadora não possuir domínio em outros idiomas, artigos disponíveis e completos na íntegra, sem a delimitação do período de publicação. As bases de dados escolhidas foram o Portal de Periódicos da Coordenação para o Aperfeiçoamento de Pessoal de Nível Superior (CAPES), o Scientific Electronic Library Online (SciELO), o Portal Regional da Biblioteca Virtual em Saúde (Portal BVS), o PubMed e o Google acadêmico.

Os descritores utilizados nas buscas foram 'ensino híbrido', 'sala de aula invertida', 'educação em saúde', 'ensino em saúde', 'fisioterapia', 'metodologias ativas', 'ensino' e 'incontinência urinária'. A busca e a seleção dos artigos foram realizadas no período de novembro de 2019 a janeiro de 2021, primeiramente a seleção dos artigos deu-se por leitura dos resumos e em caso de dúvidas a leitura completa do artigo.

Entre o período de janeiro de 2020 a janeiro de 2021 foi realizada a leitura completa dos artigos, bem como a organização da escrita. 


\section{RESULTADOS E DISCUSSÃO}

O total de artigos encontrados foram 944, no entanto apenas 3 artigos estavam de acordo com os objetivos da pesquisa. Os resultados foram organizados em dois tópicos denominados em Ensino Híbrido na área da Fisioterapia e Sala de Aula Invertida na área da Fisioterapia. Além disso, há um tópico em que apresenta uma discussão sobre pesquisas da área da saúde e a hibridização no ensino na área.

\subsection{Ensino Híbrido na área da Fisioterapia}

Os critérios de inclusão para o processo de busca foram artigos no idioma português, disponíveis e completos na íntegra no período das buscas, nas bases de dados delimitadas. Outro critério de inclusão eram os estudos que obtinham a utilização do Ensino Híbrido como abordagem no ensino no curso superior de Fisioterapia, do mesmo modo que o Ensino Híbrido como abordagem no ensino do conteúdo de Incontinência Urinária na saúde da mulher no curso de Graduação em Fisioterapia.

O total de documentos encontrados foram 621, no entanto, foram excluídos 619 resultando assim em 02 artigos. Os critérios de exclusão foram as publicações que não se configuravam como artigos científicos. Aqueles que não estavam disponíveis e completos na íntegra no período das buscas, no idioma diferente do português, artigos duplicados, assim como, não obtinham em sua premissa a abordagem do Ensino Híbrido no curso superior de Fisioterapia.

Os resultados de busca dos artigos são demonstrados na Tabela 1.

Tabela 1: Estratégias de buscas de artigos sobre Ensino Híbrido no ensino em Fisioterapia.

\begin{tabular}{|c|c|c|c|c|}
\hline Busca & $\begin{array}{l}\text { Base de } \\
\text { dados }\end{array}$ & Descritores & $\begin{array}{l}\text { Documentos } \\
\text { encontrados }\end{array}$ & $\begin{array}{c}\text { Selecionado } \\
\text { s }\end{array}$ \\
\hline 10 & SciELO & $\begin{array}{l}\text { "ensino híbrido"; "educação em } \\
\text { saúde"; "fisioterapia". }\end{array}$ & 0 & 0 \\
\hline 20 & SciELO & $\begin{array}{l}\text { "ensino híbrido"; "ensino em saúde", } \\
\text { "fisioterapia". }\end{array}$ & 0 & 0 \\
\hline 30 & SciELO & "ensino híbrido"; "fisioterapia". & 0 & 0 \\
\hline 40 & Portal BVS & $\begin{array}{l}\text { "ensino híbrido"; "educação em } \\
\text { saúde"; "fisioterapia". }\end{array}$ & 02 & 0 \\
\hline 50 & Portal BVS & $\begin{array}{l}\text { "ensino híbrido"; "ensino em saúde"; } \\
\text { "fisioterapia". }\end{array}$ & 02 & 0 \\
\hline 60 & Portal BVS & "ensino híbrido"; "fisioterapia". & 02 & 0 \\
\hline 70 & Portal CAPES & "ensino híbrido"; "fisioterapia". & 07 & 01 \\
\hline $8^{\circ}$ & Portal CAPES & "ensino híbrido"; "ensino em saúde". & 184 & 0 \\
\hline 90 & PubMed & $\begin{array}{l}\text { "ensino híbrido"; "educação em } \\
\text { saúde"; "fisioterapia". }\end{array}$ & 0 & 0 \\
\hline $10^{\circ}$ & PubMed & $\begin{array}{l}\text { "ensino híbrido"; "ensino em saúde"; } \\
\text { "fisioterapia". }\end{array}$ & 0 & 0 \\
\hline $11^{0}$ & SciELO & $\begin{array}{l}\text { "ensino híbrido"; } \quad \text { "metodologias } \\
\text { ativas"; "fisioterapia". }\end{array}$ & 0 & 0 \\
\hline $12^{\circ}$ & SciELO & "metodologias ativas"; "fisioterapia". & 0 & 0 \\
\hline
\end{tabular}




\begin{tabular}{|c|c|c|c|c|}
\hline $13^{\circ}$ & SciELO & "fisioterapia"; "ensino em saúde". & 01 & 0 \\
\hline 140 & Portal BVS & $\begin{array}{l}\text { "ensino híbrido"; "metodologias } \\
\text { ativas"; "fisioterapia". }\end{array}$ & 0 & 0 \\
\hline $15^{\circ}$ & Portal BVS & "metodologias ativas"; "fisioterapia". & 03 & 0 \\
\hline $16^{\circ}$ & Portal BVS & $\begin{array}{l}\text { "metodologias ativas"; "ensino em } \\
\text { saúde". }\end{array}$ & 169 & 0 \\
\hline 170 & $\begin{array}{c}\text { Google } \\
\text { acadêmico }\end{array}$ & $\begin{array}{l}\text { "fisioterapia"; "sala de aula } \\
\text { invertida"; "ensino híbrido". }\end{array}$ & 230 & 01 \\
\hline $18^{\circ}$ & SCIELO & $\begin{array}{l}\text { "fisioterapia"; } \\
\text { urinária"; "ensino híbrido". }\end{array}$ & 0 & 0 \\
\hline 190 & SciELO & $\begin{array}{l}\text { "ensino híbrido"; "incontinência } \\
\text { urinária". }\end{array}$ & 0 & 0 \\
\hline $20^{\circ}$ & Portal BVS & $\begin{array}{l}\text { "fisioterapia"; } \quad \text { "incontinência } \\
\text { urinária"; "ensino híbrido". }\end{array}$ & 0 & 0 \\
\hline $21^{\circ}$ & Portal BVS & $\begin{array}{l}\text { "ensino híbrido"; } \quad \text { "incontinência } \\
\text { urinária". }\end{array}$ & 0 & 0 \\
\hline $22^{\circ}$ & $\begin{array}{l}\text { Google } \\
\text { acadêmico }\end{array}$ & $\begin{array}{l}\text { "incontinência urinária"; "ensino } \\
\text { híbrido"; "sala de aula invertida". }\end{array}$ & 20 & 0 \\
\hline 230 & Portal CAPES & $\begin{array}{l}\text { "ensino híbrido"; } \quad \text { "incontinência } \\
\text { urinária". }\end{array}$ & 01 & 0 \\
\hline 240 & PubMed & $\begin{array}{l}\text { "ensino híbrido"; } \quad \text { "incontinência } \\
\text { urinária". }\end{array}$ & 0 & 0 \\
\hline $25^{\circ}$ & PubMed & $\begin{array}{l}\text { "ensino híbrido"; "fisioterapia"; } \\
\text { "incontinência urinária". }\end{array}$ & 0 & 0 \\
\hline Total & & & 621 & 02 \\
\hline
\end{tabular}

Fonte: Elaborado pela autora (2020).

Foram excluídos também aqueles artigos científicos que delinearam em conjunto com a Fisioterapia outras áreas da saúde. Do mesmo modo, aqueles artigos que obtinham em suas premissas a intervenção fisioterapêutica. Após as estratégias de buscas demonstradas na Tabela 1, os resultados da mesma foram dispostos na Quadro 1.

Quadro 1: Artigos selecionados na revisão referente ao Ensino Híbrido no ensino em Fisioterapia.

\begin{tabular}{|l|c|l|l|c|}
\hline Autores & $\begin{array}{c}\text { Ano de } \\
\text { publicação }\end{array}$ & \multicolumn{1}{|c|}{ Periódico } & \multicolumn{1}{|c|}{ Título } & Estudo \\
\hline Silva et al. & 2019 & $\begin{array}{l}\text { Revista de Ensino, } \\
\text { Educação e e } \\
\text { Ciências Humanas }\end{array}$ & $\begin{array}{l}\text { Disciplinas Híbridas: O olhar de uma } \\
\text { professora sobre sua prática em um curso } \\
\text { de fisioterapia. }\end{array}$ & E1 \\
\hline $\begin{array}{l}\text { Di Lêu; } \\
\text { González. }\end{array}$ & 2019 & $\begin{array}{l}\text { Revista Científica } \\
\text { de Iniciación a La } \\
\text { Investigación }\end{array}$ & $\begin{array}{l}\text { A Influência do Ensino Híbrido no Processo } \\
\text { de Aprendizagem dos Estudantes num } \\
\text { Curso de Fisioterapia em uma Instituição } \\
\text { de Ensino Superior da Cidade do Recife-PE. }\end{array}$ & E2 \\
\hline
\end{tabular}

Fonte: Elaborado pela autora (2020). 
No estudo E1 o objetivo foi identificar as práticas de uma professora de um curso de Graduação em Fisioterapia de uma Instituição de Ensino Superior privada do Distrito Federal, Brasil. As disciplinas ministradas pela professora eram fundamentadas no Ensino Híbrido, mas não foram descritas no estudo, segundo o mesmo, a docente foi escolhida em um universo de sete professores, porque ministrava as disciplinas por um período maior em relação aos demais (SILVA et al., 2019).

Sendo assim, o estudo E1 consistiu em uma abordagem qualitativa que obteve como instrumento de coleta de dados uma entrevista semiestruturada. A pesquisa discorreu pelas pautas sobre a concepção da docente em relação ao Ensino Híbrido, a percepção da efetividade do mesmo em relação a formação de fisioterapeutas, a compressão das práticas e as dificuldades enfrentadas pela professora frente a essa temática (SILVA et al., 2019).

Os resultados demonstrados pelo $\mathrm{E} 1$ foram de que a docente possuía o entendimento limitado das possibilidades do Ensino Híbrido. Além disso, a efetividade dessa abordagem em disciplinas na formação do profissional de Fisioterapia foi compreendida pela flexibilidade em relação aos benefícios de espaço e tempo, mas não houve especificidades em relação a formação do profissional (SILVA et al., 2019).

Outrossim, em relação as práticas com a abordagem, o estudo evidenciou que a docente utilizou os laboratórios de informática e o Ambiente Virtual disponibilizado pela Instituição, mas a mesma não exemplificou as ações dessas práticas na formação do fisioterapeuta. As dificuldades expressadas foram a falta de autonomia dos alunos em serem protagonistas na aprendizagem e outra questão pertinente descrita foi a dos alunos não obterem criticidade nas buscas em pesquisas, desse modo, obtendo informações em fontes não confiáveis, utilizando assim, notícias falsas da Internet (SILVA et al., 2019).

No estudo E2 o objetivo foi analisar se os professores estavam preparados para ministrar aulas híbridas e se havia influência no processo de ensino e de aprendizagem no curso de Graduação em Fisioterapia de uma IES privada no munícipio de Recife, Pernambuco, Brasil. Os sujeitos pesquisados foram 16 professores e 47 alunos, ambos pertencentes ao $10^{\circ}$ período do curso (DI LÊU; GONZÁLEZ, 2019).

O estudo E2 consistiu em uma abordagem qualitativa, descritiva, com observação participante e aplicação de questionário semiestruturado com perguntas abertas e fechadas aos docentes e discentes. Os questionamentos foram pautados nos desafios e nas possibilidades dos docentes e as concepções dos mesmos frente a educação tecnológica, o nível de entendimento sobre a hibridização e a opinião dos alunos sobre essas temáticas (DI LÊU; GONZÁLEZ, 2019).

Os resultados demonstrados pelo E2 foi de que os professores permanecem receosos em relação ao ambiente híbrido, em virtude de não possuírem nessa abordagem o protagonismo no cenário, assim como, o Ambiente Virtual é caracterizado como um vilão para a relação entre o professor e o aluno. Os autores ressaltaram que isto se dá devido à falta de conhecimentos ao que tange o Ensino Híbrido, igualmente a falta de informações e habilidades com as tecnologias para a dinâmica criativa e crítica na práxis pedagógica (DI LÊU; GONZÁLEZ, 2019).

Segundo o estudo E2, o desafio evidenciado pelos docentes foi de a necessidade de ruptura da figura do professor como transmissor dos conhecimentos e os alunos assumirem o papel na busca por tais. Além disso, os alunos pesquisados evidenciaram domínio no uso das tecnologias, mas não possuíam entusiasmo com essas tecnologias inseridas em sala de aula, devido alguns colegas não 
compartilharem das vivências e não possuírem o compromisso com as atividades educacionais (DI LÊU; GONZÁLEZ, 2019).

\subsection{Sala de Aula Invertida na área da Fisioterapia}

Os critérios de inclusão durante a busca foram artigos no idioma português, disponíveis e completos na íntegra no período das buscas e nas bases de dados delimitadas. Outro critério de inclusão foram os estudos que obtinham a utilização do modelo da Sala de Aula Invertida como abordagem no ensino de curso superior de Fisioterapia, do mesmo modo que a abordagem do modelo no ensino do conteúdo de Incontinência Urinária na saúde da mulher no curso de Graduação em Fisioterapia.

O total de documentos encontrados foram 323, no entanto, foram excluídos 322 resultando assim em 01 artigo. Os critérios de exclusão foram as publicações que não se configuravam como artigos científicos. Aqueles que não estavam disponíveis e completos na íntegra no período das buscas, no idioma diferente do português, artigos duplicados, assim como, não obtinham em sua premissa a abordagem do modelo da Sala de Aula Invertida no curso superior de Fisioterapia.

As estratégias de busca dos artigos são demonstradas na Tabela 2.

Tabela 2: Estratégias de buscas de artigos sobre Sala de Aula Invertida no ensino em Fisioterapia.

\begin{tabular}{|c|c|c|c|c|}
\hline Busca & $\begin{array}{l}\text { Base de } \\
\text { dados }\end{array}$ & Descritores & $\begin{array}{l}\text { Documentos } \\
\text { encontrados }\end{array}$ & $\begin{array}{l}\text { Selecionado } \\
\mathrm{s}\end{array}$ \\
\hline 10 & SciELO & $\begin{array}{l}\text { "sala de aula invertida"; "educação } \\
\text { em saúde"; "fisioterapia". }\end{array}$ & 0 & 0 \\
\hline $2^{0}$ & SciELO & $\begin{array}{l}\text { "sala de aula invertida"; "ensino em } \\
\text { saúde"; "fisioterapia". }\end{array}$ & 0 & 0 \\
\hline 30 & SciELO & "sala de aula invertida"; "fisioterapia". & 0 & 0 \\
\hline 40 & Portal BVS & $\begin{array}{l}\text { "sala de aula invertida"; "educação } \\
\text { em saúde"; "fisioterapia". }\end{array}$ & 0 & 0 \\
\hline $5^{0}$ & Portal BVS & $\begin{array}{l}\text { "sala de aula invertida"; "ensino em } \\
\text { saúde"; "fisioterapia". }\end{array}$ & 0 & 0 \\
\hline $6^{0}$ & Portal BVS & "sala de aula invertida"; "fisioterapia". & 0 & 0 \\
\hline 70 & $\begin{array}{l}\text { Portal } \\
\text { CAPES }\end{array}$ & "sala de aula invertida"; "fisioterapia". & 02 & 0 \\
\hline $8^{\circ}$ & $\begin{array}{l}\text { Portal } \\
\text { CAPES }\end{array}$ & $\begin{array}{l}\text { "sala de aula invertida"; "ensino em } \\
\text { saúde". }\end{array}$ & 21 & 0 \\
\hline 90 & PubMed & $\begin{array}{l}\text { "sala de aula invertida"; "educação } \\
\text { em saúde"; "fisioterapia". }\end{array}$ & 0 & 0 \\
\hline $10^{\circ}$ & PubMed & $\begin{array}{l}\text { "sala de aula invertida"; "ensino em } \\
\text { saúde"; "fisioterapia". }\end{array}$ & 0 & 0 \\
\hline $11^{\circ}$ & SciELO & $\begin{array}{l}\text { "sala de aula invertida"; } \\
\text { "metodologias ativas"; "fisioterapia". }\end{array}$ & 0 & 0 \\
\hline $12^{\circ}$ & SciELO & $\begin{array}{l}\text { "sala de aula invertida"; "ensino em } \\
\text { saúde". }\end{array}$ & 0 & 0 \\
\hline $13^{\circ}$ & Portal BVS & $\begin{array}{l}\text { "sala de aula invertida"; } \\
\text { "metodologias ativas". }\end{array}$ & 01 & 0 \\
\hline $14^{\circ}$ & $\begin{array}{l}\text { Google } \\
\text { acadêmico }\end{array}$ & $\begin{array}{l}\text { "fisioterapia"; "sala de aula invertida"; } \\
\text { "metodologias ativas"; "ensino } \\
\text { híbrido". }\end{array}$ & 149 & 01 \\
\hline
\end{tabular}




\begin{tabular}{|c|c|c|c|c|}
\hline $15^{\circ}$ & SciELO & $\begin{array}{l}\text { "fisioterapia"; } \\
\text { urinária"; "sala de aula invertida". }\end{array}$ & 0 & 0 \\
\hline $16^{\circ}$ & SCIELO & $\begin{array}{l}\text { "incontinência urinária"; "sala de aula } \\
\text { invertida". }\end{array}$ & 0 & 0 \\
\hline 170 & SciELO & "incontinência urinária"; "ensino". & 08 & 0 \\
\hline $18^{\circ}$ & Portal BVS & $\begin{array}{l}\text { "fisioterapia"; } \\
\text { urinária"; "sala de aula invertida". }\end{array}$ & 0 & 0 \\
\hline 190 & Portal BVS & $\begin{array}{l}\text { "incontinência urinária"; "sala de aula } \\
\text { invertida". }\end{array}$ & 0 & 0 \\
\hline $20^{\circ}$ & $\begin{array}{l}\text { Google } \\
\text { acadêmico }\end{array}$ & $\begin{array}{l}\text { "incontinência urinária"; "ensino"; } \\
\text { "sala de aula invertida". }\end{array}$ & 88 & 0 \\
\hline $21^{\circ}$ & $\begin{array}{l}\text { Portal } \\
\text { CAPES }\end{array}$ & $\begin{array}{l}\text { "sala de aula invertida"; } \\
\text { "incontinência urinária". }\end{array}$ & 0 & 0 \\
\hline $22^{\circ}$ & $\begin{array}{l}\text { Portal } \\
\text { CAPES }\end{array}$ & "ensino"; "incontinência urinária". & 54 & 0 \\
\hline $23^{\circ}$ & PubMed & $\begin{array}{l}\text { "sala de aula invertida"; } \\
\text { "incontinência urinária". }\end{array}$ & 0 & 0 \\
\hline 240 & PubMed & $\begin{array}{l}\text { "sala de aula invertida"; "fisioterapia"; } \\
\text { "incontinência urinária". }\end{array}$ & 0 & 0 \\
\hline Total & & & 323 & 01 \\
\hline
\end{tabular}

Fonte: Elaborado pela autora (2020).

Igualmente ao tópico anterior, nessa seção foram excluídos aqueles artigos científicos que delinearam em conjunto com a Fisioterapia outras áreas da saúde e aqueles que obtinham em suas premissas a intervenção fisioterapêutica. Após as estratégias de buscas demonstradas na Tabela 2, os resultados da mesma foram dispostos na Quadro 2.

Quadro 2: Artigo selecionado na revisão alusiva a Sala de Aula Invertida no ensino em Fisioterapia.

\begin{tabular}{|c|c|c|c|c|}
\hline Autores & $\begin{array}{c}\text { Ano de } \\
\text { publicação }\end{array}$ & Periódico & Título & Estudo \\
\hline $\begin{array}{l}\text { Casellato; } \\
\text { Carneiro; } \\
\text { Marchiori. }\end{array}$ & 2018 & Revista Faculdades do Saber & $\begin{array}{l}\text { A Interface de Metodologias } \\
\text { Ativas no Curso de Graduação } \\
\text { em Fisioterapia }\end{array}$ & E3 \\
\hline
\end{tabular}

Fonte: Elaborado pela autora (2020).

No estudo E3 o objetivo foi utilizar os recursos pedagógicos de metodologias ativas, durante as aulas ministradas na disciplina de Saúde Pública e Epidemiologia no curso de Graduação em Fisioterapia em uma IES privada no Estado de São Paulo, Brasil. Segundo o estudo, a disciplina era composta por 11 alunos (CASELLATO; CARNEIRO; MARCHIORI, 2018).

De acordo com o estudo E3, as ferramentas de metodologias ativas utilizadas foram "a aula invertida, dinâmica de equipe, o ensino híbrido, estratégias de ensino aprendizagem, textos sobre as mudanças na Educação em Saúde." (CASELLATO; CARNEIRO; MARCHIORI, 2018, p. 417). Para preparar a disciplina foi realizado um levantamento bibliográfico com artigos científicos na base de dados SciELO e livros da área de pedagogia (CASELLATO; CARNEIRO; MARCHIORI, 2018).

Os autores relataram que as estratégias pedagógicas vivenciadas proporcionaram dinâmica ao conteúdo. Contudo, o estudo E3 não esclarece detalhadamente como foi conduzido o modelo da Sala de Aula Invertida na disciplina do curso. Superficialmente, as atividades foram evidenciadas como 
rodas de discussão, textos para reflexão, atividades em grupos e filmes de curta duração, sem especificidade no planejamento e execução em relação ao modelo (CASELLATO; CARNEIRO; MARCHIORI, 2018).

\subsection{Considerações sobre a hibridização no ensino na área da saúde}

Os resultados encontrados nesta revisão demonstraram o número exíguo de artigos publicados no idioma português e em bases de dados de referência no país, abordando o tema da Sala de Aula Invertida no ensino de Fisioterapia, assim como, na busca de forma ampla pelo Ensino Híbrido nessa área. Ademais, se a pesquisa consistir nessas temáticas direcionadas aos docentes para o ensino do conteúdo de Incontinência Urinária Feminina, como foi observado, são inexistentes.

Foi realizado também o método denominado de Bola de Neve ou Snowball, em que consiste na identificação de pesquisas potencialmente relevantes para a dissertação nas referências dos artigos resultantes da revisão de literatura (DERMEVAL; COELHO; BITTENCOURT, 2020). No entanto nenhuma das referências bibliográficas dos três artigos resultantes da revisão contemplavam os objetivos.

Acredita-se que o ensino na área da saúde vem incorporando de maneira lenta, ferramentas e recursos tecnológicos e as Metodologias Ativas em sua vasta utilização como o Ensino Híbrido, ressignificando as interações presenciais e virtuais para a construção dos conhecimentos. Algumas especialidades da área da saúde vêm rompendo com a transmissão de conteúdo do modelo tradicional de ensino e de aprendizagem, transformando o olhar pragmático dessa área em possibilidades para se adequar as inovações tecnológicas.

No estudo de Costa et al. (2017), por exemplo, os autores procuraram descrever como o modelo acadêmico da Kroton Learning System 2.0 (KLS 2.0) era utilizado em um curso de Graduação em Enfermagem de uma IES. Uma das particularidades inseridas no KLS 2.0 é o modelo da Sala de Aula Invertida e, segundo o estudo, essas características impactam na formação do enfermeiro, como por exemplo, com uma visão crítica e reflexiva perante a realidade, o que auxilia no enfrentamento de problemas na atividade profissional (COSTA et al., 2017).

A área da Enfermagem tem se desdobrado perante as pesquisas sobre modelos ativos no processo de ensino e de aprendizagem. Por conseguinte, a área vem desenvolvendo a percepção na formação de seus profissionais no que demanda a responsabilização pelo autoestudo, a aproximação do planejamento das disciplinas em relação ao contexto dos alunos e a multiplicidade de recursos que podem ser contemplados nesses planejamentos, resultando na motivação dos alunos em suas diversas maneiras de aprender (ALVES et al.; MENEGAZ et al., 2018; FÉLIX; SOARES; GHEZZI et al., 2019).

A área da Medicina também tem demonstrado interesse em ressignificar o processo de ensino e de aprendizagem frente aos temas de Ensino Híbrido e o modelo da Sala de Aula Invertida. Algumas pesquisas evidenciam a busca por essas abordagens, no entanto, essas publicações científicas se direcionam para o delineamento da percepção dos alunos acerca da mesma, bem como ressaltam os escassos números de publicações científicas sobre a temática em suas áreas (FERMOZELLI; CESARETTI; BARBO, 2017; GOUDOURIS; STRUCHINER, 2015; COSTA et al., 2020; RIBEIRO, 2018).

Em número ainda mais exíguos, há na literatura pesquisas com a temática na área da Odontologia, no entanto, com resultados otimistas em relação ao modelo da Sala de Aula Invertida. Em virtude de 
os alunos relatarem motivação ao realizar as atividades e satisfação com o desenvolvimento dos conteúdos no modelo, isso se dá devido a um tempo superior de interação com o professor, pois nessa abordagem o papel do docente está relacionado a um orientador ao invés de transmitir os conhecimentos como no modelo tradicional expositivo (MELO JUNIOR et al., 2018; ZANON et al., 2015; NARVAI et al., 2018).

No estudo de Oliveira (2019), o modelo da Sala de Aula Invertida foi aplicado na disciplina de Higiene e Legislação Sanitária de Alimentos no curso de Graduação em Nutrição de uma IES do estado de Santa Catarina, Brasil. O interesse em aplicar o modelo partiu da docente, segundo a pesquisa, deuse pela inquietação em trabalhar a disciplina de modo lúdico e diferenciado (OLIVEIRA, 2019).

Nesse estudo na área da Nutrição, o autor relatou que a experiência do modelo da Sala de Aula Invertida foi positiva e que o modelo exige um planejamento adequado prévio, contudo, oferece o aumento da interação dos envolvidos na dinâmica do aprender e do ensinar, fomenta a criatividade nesse meio. Um aspecto evidenciado pelo estudo foi de que o modelo não requer recursos financeiros ou de tecnologias extravagantes para ser colocado em prática, e sim, de um planejamento adequado que estimule os envolvidos e seja eficaz no seu objetivo (OLIVEIRA, 2019).

Em síntese, a escassez de publicações e também a falta de variedade dessas publicações na implementação do modelo nas especialidades da área da saúde, pode influenciar no receio dos docentes em colocar o modelo da Sala de Aula Invertida em prática. Assim como, acredita-se que qualquer outro modelo de ensino e de aprendizagem que diferencie do tradicional expositivo, seja encarado como algo eventual e não regular, pois prevalece o modo como se foi ensinado.

\section{CONSIDERAÇÕES FINAIS}

Esta revisão permitiu a observação frente a temática do modelo da Sala de Aula Invertida no ensino de Fisioterapia e especificadamente no conteúdo delimitado de Incontinência Urinária Feminina. Como a escassez de publicações científicas destinadas aos docentes da área se torna uma fragilidade e acredita-se que com isso, há angústias e receios para a aplicabilidade do modelo, seja esse o da Sala de Aula Invertida seja qualquer outro modelo híbrido.

Contudo, as reflexões frente a outras propostas para o processo de ensino e de aprendizagem na área da Fisioterapia e/ou para a área da saúde de modo amplo se fazem pertinentes em relação ao atual contexto da sociedade, do mesmo modo que as possibilidades de diversificação e estímulos no âmbito educacional. Os sujeitos envolvidos no processo de ensino e de aprendizagem necessitam de subsídios que comportem o avanço no conhecimento entrelaçados a contemporaneidade.

Em suma, este artigo, mesmo que sendo um recorte, exprime o fomento em propostas educacionais em que possibilitem aos envolvidos nesse processo o estímulo a inovação, a autonomia, o protagonismo, a criatividade e a criticidade. É importante destacar também a necessidade de outras pesquisas referente a temática abordada neste artigo, em que possam evidenciar potencialidades e fragilidades do modelo da Sala de Aula Invertida no ensino do conteúdo de Incontinência Urinária Feminina ou em outros conteúdos na área da Fisioterapia. 


\section{REFERÊNCIAS}

ALVES, Tamiris Pinheiro, et al. Uso da Metodologia Ativa na Disciplina Cuidados de Enfermagem ao idoso: Relato de experiência. Anais da IV Semana de Enfermagem das Faculdades São José, Rio de Janeiro, 2018. Disponível em:

https://acervomais.com.br/index.php/saude/article/download/171/72/. Acesso em: 01 maio 2020.

APUNG, Associação Portuguesa de Urologia. Dossier Incontinência Urinária. 2013. Disponível em:

http://www.apurologia.pt/incontinencia/incontinencia_2013/Dossier_Imprensa_Incontinencia_Urina ria.pdf. Acesso: 09 jan. 2021.

BACICH, Lilian; TANSI NETO, Adolfo.; TREVISAN, Fernando de Mello. Ensino Híbrido:

Personalização e tecnologia na educação. BACICH, Lilian; TANSI NETO, Adolfo.; TREVISAN, Fernando de Mello (orgs). Ensino Híbrido: Personalização e tecnologia na educação. Porto Alegre: Penso, 2015.

CAMILLO, Cíntia. Morales; VARGAS, Manuela Eliza Gularte; MEDEIROS, Liziany Muller. Ensino Híbrido: A sala de aula invertida como possibilidade de ensino e aprendizagem. Ciclo Revista: Experiências em formação no IFGoiano, v. 3, n. 1, 2018. Disponível em: https://www.ifgoiano.edu.br/periodicos/index.php/ciclo/article/view/854. Acesso em: 06 jan. 2020.

CASELLATO, Thaís Fernanda Leitão; CARNEIRO, Richard William; MARCHIORI, Nidia Mara. A Interface de Metodologias Ativas no Curso de Graduação em Fisioterapia. Revista Faculdades do Saber, v. 3, n. 06, p. 415-420, 2018. Disponível em: https://rfs.emnuvens.com.br/rfs/article/view/53. Acesso em: 11 dez. 2019.

CAVENAGUI, Simone, et al. Efeitos da Fisioterapia na Incontinência Urinária Feminina. Revista Pesquisa em Fisioterapia, v. 10, n. 4, p. 658-665, 2020. Disponível em: https://www5.bahiana.edu.br/index.php/fisioterapia/article/view/3260. Acesso em: 10 jan. 2021.

CHRISTENSEN, Clayton M.; HORN, Michael B.; STAKER, Heather. Ensino Híbrido: uma Inovação Disruptiva? Uma introdução à teoria dos híbridos. 2013. E-book. Disponível em: http://porvir.org/wp-content/uploads/2014/08/PT_Is-K-12-blended-learning-disruptive-Final.pdf. Acesso em: 06 jan. 2020.

COSTA, Daniele Bernardi da, et al. Kroton Learning System 2.0: Modelo acadêmico utilizado em um curso de graduação em enfermagem à distância. Anais do $23^{\circ}$ Congresso Internacional ABED de Educação a Distância, 2017. Disponível em:

http://www.abed.org.br/congresso2017/trabalhos/pdf/372.pdf. Acesso em: 05 jan. 2020.

COSTA, Franciely Vanessa, et al. Uso de Estratégias Inovadoras no Ensino de Hematologia: Uma experiência na educação médica. Research, Society and Development, v. 9, n. 5, e36953181, 2020. Disponível em: https://rsd.unifei.edu.br/index.php/rsd/article/view/3181/2360. Acesso em: 02 maio 2020.

DEDICAÇÃO, Anny Caroline, et al. Comparação da Qualidade de Vida nos Diferentes Tipos de Incontinência Urinária Feminina. Revista Brasileira de Fisioterapia, v. 13, n. 2, p. 116-122, 2009. Disponível em: https://www.scielo.br/pdf/rbfis/v13n2/aop012_09.pdf. Acesso: 08 jan. 2021.

DERMEVAL, Diego; COELHO, Jorge Artur Peçanha de Miranda; BITTENCOURT, Ig Ibert. Mapeamento Sistemático e Revisão Sistemática da Literatura em Informática na Educação. In: JAQUES, Patrícia Augustin; SIQUEIRA; Sean; BITTENCOURT, Ig; PIMENTEL, Mariano. (Org.) 
Metodologia de Pesquisa Científica em Informática na Educação: Abordagem Quantitativa. Porto Alegre: SBC, 2020. Disponível em: https://metodologia.ceie-br.org/livro-2. Acesso: 26 ago. 2020.

DI LÊU, Maria de Fátima Araújo; GONZÁLEZ, Daniel. A Influência do Ensino Híbrido no Processo de Aprendizagem dos Estudantes num Curso de Fisioterapia Em Uma Instituição de Ensino Superior da Cidade do Recife-PE. Revista Científica de Iniciación a La Investigación, v. 4, n. 1, 2019. Disponível em: http://revistacientifica.uaa.edu.py/index.php/rcuaa/article/view/564/418. Acesso em: 02 fev. 2020.

FELIX, Adriana Maria da Silva; SOARES, Rosimeire Angela Queiroz. Metodologias Ativas no Ensino de Enfermagem em Doenças Transmissíveis. Revista de Enfermagem UFPE on line, v. 13, e241816, 2019. Disponível em:

https://periodicos.ufpe.br/revistas/revistaenfermagem/article/view/241816. Acesso em: 01 maio 2020.

FERMOZELLI, Juliana Abeche; CESARETTI, Mario Luís Ribeiro; BARBO, Maria Lourdes Peris. Estratégias de Blended Learning (Ensino Híbrido) no Ensino de Patologia Geral em um Curso de Medicina. Jornal Brasileiro de Patologia e Medicina Laboratorial, v. 53, n. 3, p. 202-209, 2017. Disponível em: https://www.jbpml.org.br/detalhes/327/estrategias-de-blended-learning-ensino-hibrido--no-ensino-de-patologia-geral-em-um-curso-de-medicina. Acesso em: 02 maio 2020.

FÜHR, Regina Cândida. A Tecnopedagogia na Esteira da Educação 4.0: Aprender a aprender na cultura digital. Educação no Século XXI - Volume 31 - Tecnologias/ Organização: Editora Poisson Belo Horizonte - MG: Poisson, 2019. Disponível em:

https://www.poisson.com.br/livros/educacao/volume31/Educacao_no_seculoXXI_vol31.pdf. Acesso em: 03 fev. 2020.

FÜHR, Regina Cândida. Educação 4.0 e Seus Impactos no Século XXI. V Congresso Nacional de Educação - V CONEDU, v. 1, 2018a, ISSN 2358-8829. Disponível em:

https://www.editorarealize.com.br/revistas/conedu/trabalhos/TRABALHO_EV117_MD4_SA19_ID529 5_31082018230201.pdf. Acesso em: 27 dez. 2019.

FÜHR, Regina Cândida. (Re)apreender a Docência no Contexto da Educação Digital. Revista De Educação ANEC, v. 44, n. 157, p. 92-107, 2018b. Disponível em:

http://revistas.anec.org.br/index.php/revistaeducacao/article/view/173. Acesso em: 02 jan. 2020.

GALVÃO, Taís Freire; PEREIRA, Maurício Gomes. Revisões Sistemáticas da literatura: Passos para sua elaboração. Epidemiologia e Serviços em Saúde, v. 23, n. 1, p. 183-184, 2014. Disponível em: https://www.scielo.br/pdf/ress/v23n1/2237-9622-ress-23-01-00183.pdf. Acesso em: 23 jul. 2020.

GUEDES, Janesca Mansur; SEBBEN, Vanessa. Incontinência Urinária no Idoso: Abordagem fisioterapêutica. RBCEH - Revista Brasileira de Ciências do Envelhecimento Humano, v. 3, n. 1, p. 105-113, 2006. Disponível em: http://seer.upf.br/index.php/rbceh/article/view/52/45. Acesso: 20 out. 2020.

GHEZZI, Joyce Fernanda Soares Albino, et al. Metodologias de Aprendizagem Ativa e a Formação do Enfermeiro com Pensamento Crítico: Revisão integrativa da literatura. Congresso Ibero-

Americano de Investigação Qualitativa - CIAIQ2019, v. 1, p. 478-487, 2019. Disponível em: https://proceedings.ciaiq.org/index.php/CIAIQ2019/article/view/2186/2111. Acesso em: 01 maio 2020. 
GOUDOURIS, Ekaterini; STRUCHINER, Miriam. Aprendizagem Híbrida na Educação Médica: Uma revisão sistemática. Revista Brasileira de Educação Médica, v. 39, n. 4, p. 620-629, 2015. Disponível em: https://www.scielo.br/pdf/rbem/v39n4/1981-5271-rbem-39-4-0620.pdf. Acesso em: 01 mai. 2020.

HENKES, Daniela Fernanda, et al. Incontinência Urinária: O impacto na vida de mulheres acometidas e o significado do tratamento fisioterapêutico. Semina: Ciências Biológicas e da Saúde, v. 36, n. 2, p. 45-56, 2015. Disponível em:

http://www.uel.br/revistas/uel/index.php/seminabio/article/view/21746. Acesso em: 10 jan. 2021.

MARQUES, Keila Simone Frade; FREITAS, Patrícia Antônia Corrêa de. A Cinesioterapia Como Tratamento da Incontinência Urinária na Unidade Básica de Saúde. Fisioterapia em Movimento, v. 18 , n. 4, p. 63-67, 2005. Disponível em:

https://periodicos.pucpr.br/index.php/fisio/article/view/18646/18064. Acesso: 12 out. 2020.

MASCARENHAS, Teresa. Disfunções do Pavimento Pélvico: Incontinência urinária e prolapso dos órgãos pélvicos. Manual de Ginecologia, v. 2, p. 97-130, 2011.

MATOS, Mirelle Aires Botelho de, et al. As Repercussões Causadas pela Incontinência Urinária na Qualidade de Vida do Idoso. Revista de Pesquisa: Cuidado é Fundamental Online, v. 11, n. 3, p. 567-575, 2019. Disponível em:

http://seer.unirio.br/index.php/cuidadofundamental/article/view/6581. Acesso em: 15 out. 2020.

MELO JUNIOR, Paulo Mauricio Reis de, et al. Sala de Aula Invertida para o Ensino do Conteúdo Abertura Coronária em Endodontia. Revista da ABENO, v. 18, n. 2, p. 182-191, 2018. Disponível em: https://revabeno.emnuvens.com.br/revabeno/article/view/584. Acesso em: 02 maio 2020.

MENEGAZ, Jouhanna do Carmo, et al. Flipped Classroom no Ensino de Gerenciamento em Enfermagem: Relato de experiência. Escola Anna Nery, v. 22, n. 3, p. 01-07, 2018. Disponível em: https://www.scielo.br/pdf/ean/v22n3/pt_1414-8145-ean-22-03-e20170312.pdf. Acesso em: 01 maio 2020.

MORAN, José. Educação Híbrida: Um conceito-chave para a educação, hoje. In: BACICH, Lilian; TANSI NETO, Adolfo.; TREVISAN, Fernando de Mello (orgs). Ensino Híbrido: Personalização e tecnologia na educação. Porto Alegre: Penso, 2015.

NARVAI, Paulo Capel, et al. Saúde Bucal Coletiva e pedagogia da sala de aula invertida: possibilidades e limites no ensino de graduação. Revista da ABENO, v. 18, n. 1, p. 124-133, 2018. Disponível em:

https://edisciplinas.usp.br/pluginfile.php/4170644/mod_label/intro/Narvai\%20et\%20al\%20sala\%20 invertida.pdf. Acesso em: 02 fev. 2020.

OLIVEIRA, Antônio Hérbetty Arcanjo Martins, et al. Cartilha Educativa para Mulheres Sobre Incontinência Urinária: Concepções e desenvolvimento. Revista Baiana de Saúde Pública, v. 41, n. 2, p. 308-323, 2017. Disponível em: http://rbsp.sesab.ba.gov.br/index.php/rbsp/article/view/1930/2240. Acesso em: 11 dez. 2020.

OLIVEIRA, Jaqueline Ramos de; GARCIA, Rosamaria Rodrigues. Cinesioterapia no Tratamento da Incontinência Urinária em Mulheres Idosas. Revista Brasileira de Geriatria e Gerontologia, v. 14, n. 2, p. 343-351, 2011. Disponível em: https://www.scielo.br/pdf/rbgg/v14n2/v14n2a14.pdf. Acesso: 13 out. 2020.

OLIVEIRA, Kátia Adriana Cardoso de; RODRIGUES, Ana Beatriz Cezar; PAULA, Alfredo Batista de. Técnicas Fisioterapêuticas no Tratamento e Prevenção da Incontinência Urinária de Esforço na 
Mulher. Revista Eletrônica F@pciência, v. 1, n. 1, p. 31-40, 2007. Disponível em: http://www.fap.com.br/fap-ciencia/edicao_2007/004.pdf. Acesso: 13 out. 2020.

OLIVEIRA, Renata Carvalho de. Aplicação da Metodologia Sala de Aula Invertida em Disciplina do Curso de Nutrição. Revista Redes-Revista Interdisciplinar do IELUSC, [S.I], n. 1, p. 67-76, 2019. Disponível em: http://revistaredes.ielusc.br/index.php/revistaredes/article/view/73/32. Acesso em: 01 maio 2020.

OLIVEIRA, Sabrina Guedes de. Educação Hibrida: A aprendizagem colaborativa através da sala de aula invertida. Revista Arquivos Científicos (IMMES), v. 1, n. 2, p. 38-43, 2018. Disponível em: http://arqcientificosimmes.emnuvens.com.br/abi/article/view/63/49. Acesso em: 15 jan. 2020.

PITANGUI, Ana Carolina Rodarti; SILVA, Rosemary Gonçalves da; ARAÚJO, Rodrigo Cappato de. Prevalência e Impacto da Incontinência Urinária na Qualidade de Vida de Idosas Institucionalizadas. Revista Brasileira de Geriatria e Gerontologia, v.15, n. 4, p. 619-626, 2012. Disponível em: https://www.scielo.br/pdf/rbgg/v15n4/02.pdf. Acesso em: 17 jan. 2021.

RIBEIRO, Lídia Cristina Villela. Testando Novas Metodologias de Aprendizagem para o Ensino de Embriologia Humana: Relato de experiência e percepção dos discentes. Revista Docência do Ensino Superior, v. 8, n. 1, p. 151-165, 2018. Disponível em: https://periodicos.ufmg.br/index.php/rdes/article/view/2446/1464. Acesso em: 02 maio 2020.

ROCHA, Mayra Jaqueline; DIAS, Rafael Luiz; VIEIRA, Lizyana. Efeitos da Cirurgia Bariátrica na Incontinência Urinária. FAG Journal of Health (FJH), v. 2, n. 4, p. 466-469, 2020. Disponível em: https://fjh.fag.edu.br/index.php/fjh/article/view/257/212. Acesso em: 16 jan. 2021.

SCHENEIDERS, Luís Antônio. O Método da Sala de Aula Invertida (Flipped Classroom) / Luís Antônio Schneiders - Lajeado: Ed. da Univates, 2018. Disponível em: https://www.univates.br/editora-univates/media/publicacoes/256/pdf_256.pdf. Acesso em: 22 jan. 2020.

SILVA, Arthur Lorran Mello André da, et al. Disciplinas Híbridas: O olhar de uma professora sobre sua prática em um curso de fisioterapia. Revista de Ensino, Educação e Ciências Humanas, v. 20, n. 4, p. 341-345, 2019. Disponível em:

https://revista.pgsskroton.com/index.php/ensino/article/view/7626. Acesso em: 30 dez. 2019.

SILVA, Juliana Cristina Pereira da; SOLER, Zaida Aurora Sperli Geraldes; WYSOCKI, Anneliese Domingues. Fatores Associados à Incontinência Urinária em Mulheres Submetidas ao Exame Urodinâmico. Revista Escola de Enfermagem da USP, v. 51, e03209, 2017. Disponível em: https://www.scielo.br/pdf/reeusp/v51/pt_1980-220X-reeusp-51-e03209.pdf. Acesso: 10 jan. 2021.

SILVA, Michele Rejane Coura da; MACIEL, Cristiano. Blended Learning: Reflexões sobre o ensino semipresencial na educação superior no Brasil. Anais do XII Congresso Nacional de Educação - EDUCERE, ISSN 2176-1396, 2015. Disponível em: https://educere.bruc.com.br/arquivo/pdf2015/20231_9663.pdf. Acesso em: 06 jan. 2020.

SILVA, Michele Rejane Coura de; MACIEL, Cristiano; ALONSO, Kátia Morosov. Hibridização do Ensino nos Cursos de Graduação Presenciais das Universidades Federais: Uma análise da regulamentação. Revista Brasileira de Política e Administração da Educação - RBPAE, v. 33, n. 1, p. 95-117, 2017. Disponível em: https://seer.ufrgs.br/rbpae/article/view/74042/41701. Acesso em: 03 jan. 2020.

SOUZA, Andrezza Cristina da Silva Barros; SOUZA, Dácio Michel da Cruz; DANTAS, Deyse de Souza. Sala de Aula Invertida: Uma experiência no ensino superior. V Congresso Nacional de Educação 
- V CONEDU, V. 1, ISSN 2358-8829, 2018. Disponível em:

https://www.editorarealize.com.br/revistas/conedu/trabalhos/TRABALHO_EV117_MD1_SA19_ID609 7_10092018231955.pdf. Acesso em: 29 dez. 2019.

SUNAGA, Alexsandro; CARVALHO, Camila Sanches de. As Tecnologias Digitais no Ensino Híbrido. In: BACICH, Lilian; TANSI NETO, Adolfo.; TREVISAN, Fernando de Mello (orgs). Ensino Híbrido: Personalização e tecnologia na educação. Porto Alegre: Penso, 2015.

VALENTE, José Armando. A Sala de Aula Invertida e a Possibilidade do Ensino Personalizado: Uma experiência com a graduação em midialogia. Metodologias Ativas para uma Educação Inovadora: Uma abordagem teórico-prática. Organizadores: Lilian Bacich, José Moran. - Porto Alegre: Penso, 2018b.

VALENTE, José Armando. Blended Learning e As Mudanças no Ensino Superior: A proposta da sala de aula invertida. Educar em Revista, Edição Especial, n. 4, p. 79-97, 2014a. Disponível em: http://www.scielo.br/pdf/er/nspe4/0101-4358-er-esp-04-00079.pdf. Acesso em: 20 nov. 2019.

VOGT, Alessandra; SOARES, Silviane Lawall. Prática Docente Usando o Método Flipped Classroom: Um estudo de caso em uma Instituição de Ensino Superior. $23^{\circ}$ CIAED, Congresso

Internacional ABED de Educação a Distância, 2017. Disponível em: http://www.abed.org.br/congresso2017/trabalhos/pdf/450.pdf. Acesso em: 02 fev. 2020.

ZANON, Denise Puglia, et al. Sala de Aula Invertida: Possibilidades e limites na docência universitária. Anais do XII Congresso Nacional de Educação - EDUCERE, ISSN 2176-1396. Disponível em: https://maiza.com.br/wp-content/uploads/2017/04/Artigo-Sala-de-aula-invertidaALTHAUS-ZANON-CANCADO-SANCHES-Puc-2015.pdf. Acesso em: 03 maio 2020.

Submissão: 06/02/2021

Aceito: 16/02/2021 